\title{
The Value of Fathering for Incarcerated Offenders: Implementing the "Parents as Teachers" Curriculum in Greene County, Missouri
}

\author{
Aida Hass-Wisecup ${ }^{1}$, Erin Kenny ${ }^{2}$, Kayleb Adams-Derousse ${ }^{3}$ \\ ${ }^{1}$ Professor, Department of Criminology, Missouri State University, United States \\ ${ }^{2}$ Assistant Professor, Department of Anthropology, Missouri State University, United States \\ ${ }^{3}$ Student, Department of Criminology, Missouri State University, United States \\ Correspondence: Erin Kenny, Assistant Professor, Department of Anthropology, Missouri State University, United \\ States.
}

Received: June 4, 2021

Accepted: June 25, $2021 \quad$ Available online: June 28, 2021

doi:10.11114/ijsss.v9i4.5276

URL: https://doi.org/10.11114/ijsss.v9i4.5276

\begin{abstract}
Research literature demonstrates the positive contributions of a nurturing father in the lives of young people as well as the reduction of recidivism for active fathers. The current study provides support for this model by highlighting the need for programming that enhances the relationship between incarcerated fathers and their children during their period of absence and while transitioning back into society and their family roles. The authors observed a parenting education program for incarcerated fathers twice weekly for a period of twelve weeks. The research noted three promising themes in the programming which could be expanded and implemented in other facilities. Fathers sought to improve their capacity to engage in "intentional conversations," where they learned about modeling desirable behavior, being honest, and avoiding giving children mixed messages. Fathers also began the uncomfortable process of unpacking their own childhoods and overcoming poor parental models as they realized that "parenting makes a difference." Through the program, fathers were encouraged to develop a "toolkit" of more positive parenting responsibilities and responses. Finally, fathers were introduced to the idea of "healthy relationships," including creating strong boundaries and new types of relationship knowledge.
\end{abstract}

Keywords: fatherhood, fathering, parent education, prison programs

\section{Introduction}

For the past several decades, "get tough on crime" ideologies and rhetoric have permeated criminal justice discourse, stifling dialogue that promotes the welfare and well-being of families of incarcerated people. This, despite surmounting evidence which suggests that the incarceration of a parent leads to many changes, not only in their own lives, but in the lives of the children and family that they leave behind, changes that are riddled with social, economic, and emotional hardship and suffering (Arditti, 2012). Moreover, while incarceration may have many diverse functions in terms of providing treatment for addiction, addressing mental health concerns, protecting society from violent predators, and righting a wrong to the victim of a crime, the long-term effect that imprisonment has on the inmate's own family, especially their children, cannot be neglected from the research literature as this has a detrimental impact on the future welfare of communities and society as a whole.

The current study examines the role of parenting education programs in a correctional setting and their value in strengthening bonds between children and their fathers. The goal is to establish a research forum consistent with emerging research trends which underscore the need to explore the value of providing the necessary tools for incarcerated fathers to become more actively engaged in the process of child development in a manner that is consistent and nurturing (Hairston, 2017; McKay et al., 2010, 2015). Our objective is to investigate a program called "Strengthening Families", an evidence-based initiative that provides family skills training programming for high-risk families. We will specifically examine the "Parents as Teachers" (PAT) curriculum, offered weekly by facilitators from Springfield Public Schools at the Greene County Jail (GCJ) in Springfield, MO. The program is tailored to provide education, resources, and support services where needed, to incarcerated fathers and their families. The goal of the program is to improve the skills of incarcerated parents to a more confident and supportive level for their children and families in order to minimize the detrimental impact that incarceration has on the relationship between fathers and their children. 


\section{The Scope of the Problem: Why Teach Parenting to Male Offenders?}

It is well documented in the research literature that incarcerated fathers face several barriers and obstacles in providing their children with the necessary mechanisms of support to foster a healthy relationship (Arditti, 2005; Dyer et al., 2012; Jardine, 2017). These barriers are created by the significant disenfranchisement that occurs through the incarceration experience which results in a sense of loss in children and the near impossibility of bonding with their parent through family visitation in a correctional setting. This is compounded by the incarcerated father's feeling of helplessness in providing emotional and physical support to their child while managing their own limitations in becoming involved as a caretaker and relying on the child's mother to be the gatekeeper of their interactions. Over time, the divide leads to the onset of detachment, and the reality of separation further breaks down the relationship between the incarcerated father and his child or children, a cycle the deteriorates any potential for building and strengthening the relationship as the role of parenting continues to disintegrate in the context of a correctional setting.

Within this context, the potentially positive contributions of a nurturing father suggest an urgent need to address the value of teaching parenting skills to incarcerated fathers. First, parenting education has been consistently identified as having a positive impact on developing healthy family relationships; second, while offenders may have a concern for their children, they may not always have the skills, knowledge and understanding of how to parent effectively; finally, a growing body of evidence suggests that parenting education increases the likelihood of post-release success.

\subsection{Parenting Education and Family Development}

Parenting Education programs encourage positive parenting practices intended to promote safety, well-being, and permanency for children and families. The 2010 Child Abuse Prevention and Treatment Act (CAPTA) recognizes the role of parent education programs in reducing the risk of child abuse and neglect by helping parents and caregivers acquire the skills, support, and resources they need to build healthy families and communities. Research shows that such programs can have positive impacts on the social, emotional, and intellectual development of children (NASEM, 2016; Rothe et al., 2016). When implemented in the first 8 years of a child's life, evidence-based programs find that children of parents who complete parenting education programs report a higher sense of security, greater ability to focus, and improved behavioral health (Child Welfare Information Gateway, 2019).

To maximize positive outcomes for families, parent education programs teach parents to understand the individual and developmental needs of children, as well as their own roles and responsibilities. Such programming frequently emphasizes three key areas: social learning theory; family system approaches to trauma; and additional consultation. Social learning theory encourages positive behavior by building upon the parent-child connection. Parents are taught to be more attentive to the cues of their children to understand and respond in ways that reinforce positive behaviors. Family system approaches emphasize skills-based interventions to improve child behavior and to minimize caregiver distress by training parents to recognize and reward positive changes in attitude, as well as to identify emerging feelings of self-esteem and self-mastery. Occasionally, parent education programs rely on counseling and professional consultation to improve attachment between parents and children, to help families better understand emotional needs, and to enhance stability within the home. Across the nation, parent education programs have demonstrated significant benefits for parents, caregivers, families, and communities. These skills lead to more positive parenting styles as a result of greater understanding of child development and mastery of more effective communication styles; enhanced social connections for parents as they learn to exchange ideas, provide and obtain support, and share resources with other parents; greater prosocial behavior and fewer negative externalizing behaviors in children; enhanced parental mental health and well-being associated with reduced caregiver depression, anxiety, anger, guilt, and stress; reduced risk of corporal punishment and child abuse as parents are encouraged to rethink their expectations of children and to explore alternatives to physical punishments; and increased competence and comfort with nurturing, caregiving skills, and parental self-confidence with the use of positive language, planned discipline, and family routines (Rothe et al., 2016).

Best practices in parenting education that have been found to be consistently associated with positive family outcomes include actively engaging parents either with a professional, at home, on-site with their child, or in a group setting; reaching parents early, especially in the first twelve years; including cultural adaptations to accommodate unique needs and cultural traditions of families; programs that run over several months and meet at least once a week; explicit promotion of family routines, including family activities and regular family roles; and the use of skilled parent education facilitators. Optimally, parent education facilitators should be like the demographic makeup of the participants and cultivate qualities of warmth, genuineness, flexibility, humor, and empathy, as well as strong communication skills honed closely to active listening, sensitivity to family and group processes, and personal credibility built on a history of relationships with children (Huser et al., 2008).

Additionally, programs that target paternal parenting skills and development of healthy relationships offer an opportunity to examine how nonresident fathers can build attachments with children despite their absence in the daily lives of children 
(Children \& Family Research Partnerships, 2016). Parent training programs serve families by providing child development information about appropriate activities for achieving milestones, modeling positive and healthy relationships, and teaching incarcerated parents to improve their parenting skills to make a difference in their children's lives.

\subsection{Incarceration and its Effect on Parenting}

Society today is at an all-time high in terms of the demands on time that is placed on each individual household. We commonly hear people say "where did the time go" or "there are not enough hours in the day." Ironically, this concept of having little to no time to get things done is far from reality within a prison setting. Some prisoners describe "doing time" as one of the most difficult challenges of being in prison, akin to watching the hands on a clock move and counting every second of that movement (Mitchell et al., 2018). To make this process less painful, some incarcerated men and women engage in a variety of activities to pass the time, joining self-help groups, attending religious worship services, participating in sporting activities, and learning a new trade or working at a job; others isolate themselves, become secluded, or join in the illegal activities of prison contraband economics. A common theme uniting the inmate experience, however, seems to be the dimension of personal reflection that emerges as the individual offender processes their life choices. Past regrets, letdowns, and disappointments become the defining points of the present and many improvement attempts may be stifled by the uncertainty of the future and the ability to survive in the prison environment (Fox et al., 2019).

The opportunity to support and empower offenders as they dare to dream about their futures and the well-being of their family is a strong incentive for rehabilitation. For some offenders, especially males, this process means opening the door to experience their own feelings for the very first time, in a context where the expression of emotions is perceived as a sign of weakness and a detriment to sustaining the harsh realities of prison life (Wilson, 2013). Under these circumstances, the role of education in prison encourages deep reflection of one's self and others, a possibility that redefines the boundaries of the parent-child relationship and presents unique challenges to the act of parenting.

Undeniably, fathers play a significant role in the lives of their children (Cabrera et al., 2018). It is not just the amount of contact that is integral for nurturing children, but also the quality of that contact to develop a meaningful relationship and positively impact a child's future (Sanders et al., 2014; Britto et al., 2017). One of the most difficult challenges of incarceration is creating programming that is relevant to life outside of prison walls. This includes educational programming that addresses the needs of families to co-parent children while dealing with the dynamics and realities of separation and the natural divide that creates. Studies have shown repeatedly that the forced separation of incarceration negatively impacts individuals and families, weakening communities and creating economic hardship, stigmatization, the displacement of children, and compromising relationships (Visher et al., 2013; Johnson et al., 2017; Miller, 2018).

Moreover, the prison environment itself decreases an offender's ability to cope with and understand the hardships their families are facing on the outside. Incarcerated offenders, particularly incarcerated fathers, have limited resources, knowledge, will power and patience to effectively parent their children (Wilderman, 2014; Palm, 2018). Concerned with their present state and condition, offenders are preoccupied with learning new rules, adapting to a new culture and new "normal," dealing with their own sense of shame and failure, and trying to survive physically and emotionally in their new environment. Just as the deprivation of liberty redefines the role of an offender as a caretaker and father, a feeling of despondency and confusion emerges among children, reevaluating their own role as a child and in some ways adapting to the process of visitation as a form of exercising control (Murray, 2014; Martin, 2017).

The extant literature consistently demonstrates a correlation between parental incarceration and a negative impact on the social, emotional, and psychological development of children (Haskins, 2015; Turney \& Goodsell, 2018). According to Henkhaus (2019) and Murphy and Cooper (2015), this dynamic is compounded by the parallel between parental incarceration and the contextual components of economic instability, family dysfunction, child abuse/neglect and neighborhood violence. It is not surprising, therefore, that children of incarcerated parents are at greater risk for mental illness, including depression, anxiety, and sleeping disorders, as well as behavioral problems at school (Haskins, 2015). Children with an incarcerated parent are also more likely to exhibit conduct disorders, antisocial behavior, substance abuse problems and addiction, and more likely to drop out of school or be expelled (Fontaine et al., 2017; Haskins, 2017; Lee et al., 2013). This in turn has been found to have a profound influence on the well-being of the incarcerated parent who, already in a forced state of helplessness, is dealing with the additional stress of their child's misconduct and abysmal outlook, often leading to their own behavioral issues as they feel a personal failure in their inability to effectively parent their children. According to Houck and Loper (2002), incarcerated parents who questioned their competence as parents were more likely to express feelings associated with anxiety and depression. In addition, they also had higher rates of infractions for misconduct in prison than parents who did not indicate they experienced stress related to their parenting-abilities (Houck \& Loper, 2002). Likewise, studies show that incarcerated parents who became involved in 
programming aimed at restoring their relationships with children and families were more likely to separate themselves from known troublesome inmates, as well as experience a decreased level of disciplinary action (Jeffries \& Menghraj, 2016).

According to the Bureau of Justice Statistics, $50 \%$ of offenders in State and Federal Prisons have minor children, meaning 1.7 million American children have an incarcerated parent. A few prisons across the United States have begun to incorporate parenting education into their reentry programming, specifically targeting male offenders, a much-neglected population when it comes to addressing parent-child relationships and bonds. These programs, focused on reintegrating dads into their children's lives, are built on mounting evidence that such intervention has one of the greatest outcomes in terms of improving the chance of long-term reentry success (Fontaine, 2017).

\subsection{Parenting Education and Reentry Success}

Barriers and obstacles that offenders face upon their return to the community may be minimized by involvement in training programs that contribute to success in a positive, protective way (Yong, 2016; Middlemass \& Smiley, 2019). With a significant majority of male offenders being fathers, the wide-spread impact of incarceration on families and communities prompted researchers to examine the role of parenting education and to consider its long-term effect in supporting the reentry experience and reducing the chances of recidivism.

Sociology researchers (Edin et al., 2019), found that fathers who took an active fathering role with their children while still incarcerated were also more actively engaged in legitimate employment opportunities after release and less likely to become involved in illegal activities. Researchers note that the experiences of fathers in reconnecting and reestablishing a relationship with their children after a period of incarceration vary widely; however, there is compelling evidence that developing a positive connection with children and actively taking on a parenting role while incarcerated directly impacts the chances of success during the reentry phase of prisoner release and reintegration into the community (Boswell, 2018).

Incarcerated fathers face several barriers that may stifle any attempts to maintain a close bond or connection with their children while in prison and properly develop a new model of parenting. Strained relationships between incarcerated male offenders and the mothers of their children is cited as one of the most significant obstacles that men face when trying to develop and maintain a relationship with their children (Edin et al., 2019). Moreover, the absence of the biological father in the life of the child and the child's mother often leads to the development of relationships with other male father figures that can compete with parenting attempts by incarcerated male offenders, as the emotional connection with their children is challenged by the bonds that develop with these other male role models. These issues are compounded by the additional complexities of prison rules and restrictions on visitation of children, child support and custody battles that ensue after the incarceration of a father; unrealistic expectations on the nature and frequency of contact between incarcerated fathers and their children; and the negative effect prison has on the returning father's attitudes, adjustment, and their ability to remain psychologically and emotionally connected with their families (Craigie et al. 2018; McKay et al., 2018).

These dynamics create an urgent need for the implementation of parenting programs for incarcerated male offenders that can overcome these obstacles and contribute to their successful establishing of a positive and healthy relationship with their children during their period of imprisonment. Studies have found compelling evidence to show that one of the most consistent predictors of establishing a healthy father-child relationship upon release from prison and reintegration into society is the quality of that relationship during the period of incarceration (Visher, 2013; Turner, 2017; Buston, 2018). Moreover, an Urban Institute Report (Fontaine et al., 2017) found that fathers who have more frequent and meaningful contact with their children while incarcerated, are more successful in rebuilding their relationships with their children upon reentry, maintain that the continued adaption of parenting roles while in prison helps with the transition into those roles upon release. This evidence provides support for the need to counter the dynamics of interaction that limit contact with fathers and their children while in prison, including policies that inhibit unsupervised conversations and physical contact between fathers and their children.

While some research focuses on the relationship between incarcerated male offenders and intimate partners, fewer studies explore the father-child relationship during the period of incarceration. In an ethnographic study of how incarceration shapes familial relationships for the partners of men jailed at San Quentin in California, Comfort (2009) demonstrates how the prison is constantly and emphatically present in the lives of the offender's families. She identifies the prison itself as an active agent in producing change, and calls on institutions to generate effective service delivery and policymaking, such as providing parenting skills to facilitate the reentry of incarcerated fathers. A study of reentry prisoners in Cleveland, Ohio found that fathers who co-habited with their children upon release were less likely to be involved in substance abuse after one year (Visher \& Courtney, 2007). That study also noted that prior to release, $46 \%$ of respondents indicated that fathers who had positive encounters and visits with their children while incarcerated were less likely to return to prison.

Other studies examining offender adjustment to reentry challenges after incarceration reveal similar findings. Visher et al. (2010) examined the reentry experiences of 652 prisoners released from Illinois, Ohio, and Texas in 3 waves of qualitative 
interviews conducted prior to release, and at 2 months and 7 months, after release. Their findings suggest that men who had children to whom they were more strongly attached during their period of incarceration were more likely to have success in terms of employment and substance abuse desistence after their release. Moreover, in a multi-sited U.S. Department of Health and Human Services evaluation study (2017) of 712 reentering fathers participating in a parenting initiative, researchers found a strong link between fathers who had quality communication and contact with their children during incarceration and a positive reintegration back into the community and family. Likewise, an evaluation study of a Fathers in Prison program implemented in a Norwegian prison based on interviews with inmate participants at the start of the program, as well as at the end of the program revealed that after a six month follow-up from program completion, participants expressed a heightened sense of awareness and commitment to their role as a father and its connection to desistence from criminal activity (Hansen, 2017).

These and other findings support the claim that the development and maintenance of meaningful and positive relationships between fathers and their children during incarceration can become a strong predictor of positive reentry and adjustment upon release, consistent with social support and relationship theoretical frameworks which suggest that supportive family roles and involvement with children serve as protective factors in the inhibition of criminal tendencies and promote general emotional health and wellbeing (Sippel et al., 2015; Charles et al., 2019).

\section{Parents as Teachers (PAT): Learning in Action}

"Strengthening Families at the Greene County Jail" is a program designed to provide parent education classes to offenders incarcerated in Springfield, Missouri. The goal of the program is to empower parents to improve their parenting skills, and to return to their homes with more confidence and a support network following their release from the jail. Administered by the Springfield Public Schools Parents as Teachers program, the hour-long weekly program provides education, resources, and support to inmates, with assistance from the Greene County's Sherriff's Office and the Greene County Jail (GCJ).

"Parents as Teachers" (PAT) is a popular school readiness program that aims to improve the performance of young students in the areas of mathematical concepts, rapid letter naming, and rapid vocabulary. Program organizers recognized that many incarcerated parents did not have positive parenting role models to model healthy relationships and they could not easily identify childhood developmental milestones. Group facilitators supplemented the standard PAT curriculum to focus heavily on providing information and skills necessary to support successful relationships. Through non-judgmental facilitation and self-led discussions, inmates are encouraged to explore the range of emotions that affect their situation.

For example, the group programming modules for incarcerated parents directly addresses the stages of grief that parents and children may feel when hearing that the parent is being taken into custody, including shock (an initial paralysis), denial (the tendency to resist or run when presented with the possibility of jail), bargaining (seeking in vain a way to get out of incarceration), depression (as the inevitable is realized), and acceptance. Facilitators focus on managing a transition from depression to acceptance, and to encourage incarcerated parents to start coming to terms with the complicated ways that an incarcerated parent can impact the emotional, physical, educational, and financial well-being of a family. Through the programming, parents are given tools to manage the anxiety of their circumstances and to prepare themselves for addressing these traumas in the lives of their children upon release.

The GCJ-PAT curriculum begins with an acknowledgement that change is hard, and that learning new ideas and behaviors takes time, effort, and a genuine desire to transform. According to the training materials, "Sometimes we are the first and maybe the only person to tell [incarcerated parents] it's okay. 'You made a mistake. Fix it and move forward.' We may be that one person that says something positive that flips a switch and turns them on the right path."

\section{A Qualitative Study of Greene County Inmate Fathers on Their Parenting Needs}

\subsection{Overview of Study}

In March of 2019, Aida and Erin met with Shari Nichols, Counselor at Shady Dell Early Childhood Learning Center to gain a better perspective and understanding of the program designed and implementation of the PAT curriculum, and its development into a tool belt of knowledge and information for Greene County Jail inmates. Following Institutional Review Board approval and required training for researchers and volunteers to work in Greene County Jail, Aida and Erin began to attend classes twice weekly from October of 2019 through January 2020, observing a total of 12 classes throughout this period.

"Strengthening Families at the Greene County Jail" empowers parents to improve their parenting skills by providing caregivers with knowledge, resources, and support to develop parenting skills that enhance child and family well-being. The program began in 2016 when Shari Nichols, who worked as the Director of PAT and Missy Riley, the Early Childhood Director for Springfield Public Schools identified the need for parenting classes in jail based on the needs of 
one of their staff. The program first debuted in Laclede County Jail in Lebanon, Missouri, but was transferred to the GCJ in 2017 with the assistance of the Greene County Sheriff and the President of the Springfield Public School Board.

PAT facilitators chose to use a curriculum developed for "Teen Parents" for their work with PAT in the jail. According to Shari, "most offenders start using drugs/alcohol when they are teens, some 13 to 15 years old, and that curriculum is written so that teens may comprehend, relate to, and understand the issues easier." Typically, two facilitators conduct each session with inmates at GCJ. Before arriving, the facilitator leader selects a lesson to offer. "We are using handouts and supplementing with some additional information we are gathering from a variety of resources. It is being generalized for all parents; however, some classes may move further and get into a more detailed conversation depending on where they are in their thinking" (Shari).

Classes are conducted for male offenders 3 times a week, with two facilitators leading each lesson. Although there are also classes designed for female offenders, we chose to observe the classes for incarcerated fathers, a much-neglected area of study in the research literature (McLeod et al., 2019). Each hour-long lesson includes specific lessons which may evolve into dynamic discussions between the offenders and the facilitators. We were introduced to the group as researchers interested in learning more about the "Strengthening Families at the GCJ" program and how this program addresses some of the parenting needs of incarcerated fathers.

\subsection{Methodology}

As previously noted, research documents a significant need to maintain healthy social bonds between children and their incarcerated fathers to reinforce the father's role as a parent and create a sense of permanency for children that will have a positive impact on their future development into healthy adults. In addition, the parenting role of incarcerated fathers has a direct effect on the successful reentry of offenders as they transition from prison back into society and reclaim their roles as members of their families. For these reasons, it is imperative to explore the urgent need to implement programming for incarcerated offenders, especially for male offenders, that enhances their ability to become more effective parents during their period of incarceration and upon their release and return to their children.

This need guided our study of the "Strengthening Families at the GCJ" program. Our qualitative approach gave us a more in-depth, complete understanding of the parenting needs of inmate fathers, using their own words and shared experiences, personal struggles, and self-perception of their role as parents in the lives of their children. We approached our study using a detached observation methodology that allowed us to have a limited amount of interaction with our subjects to maintain objectivity and limit the amount of emotional attachment to their stories in order to increase the validity of our findings and ensure they are free from personal bias and reactivity (Hayashi et al, 2019; Mohajan, 2018). We chose to be detached observers in this qualitative study, as we sat in the same circle around the table but did not participate in the dialogue or interaction. While taking extensive notes during the dialog, we also tried to maintain some level of eye contact and react to the shared conversation in order to keep some level of trust and identification between the researchers and the inmates. Admittedly, it was difficult to become fully detached in a session that included so much engagement between participants and facilitators as well as the raw output of emotions from the incarcerated fathers.

During our 12-week observation period, we recorded in writing the dialog that took place between the facilitators and the inmates. We wrote down thoughts, reflections, questions asked, and information shared. We did not use any names, and captured both sentiments expressed, and direct quotes where appropriate. Data collection was gathered on all possibly recorded dialog between inmates and facilitators based on our sample of offenders participating in the classes for the study. We coded our data to fit themes developed in this paper around our theoretical understanding and research of the subject as well as a review of the literature in this area. We then created categories to classify our observations into meaningful descriptive groups based on these themes. This type of data collection and analysis was used in order to allow us to engage in a continuous inductive process of discovery during our observation, including information that had not yet been developed when structuring our research design (Tracy, 2019). We were also very careful to include all information gathered through transcription to increase the reliability of the data and ensure our analysis was thorough, honest, and comprehensive, reflecting all sentiments and shared meanings expressed during group sessions (Spiers et al, 2018).

\section{Findings}

The PAT program in the GCJ for women began in November 2017. By March of 2020, 268 women had attended the class, most of these participating in multiple classes. The men's classes began the following year, in August 2018, and by March of 2020, 172 men had attended the classes, with many of them participating in multiple classes. After completing five classes, participants earn a PAT Certificate, which may potentially be persuasive in pending legal cases. To date, several incarcerated fathers at the Greene County Jail have received certificates designed to illustrate active engagement in the process of child development in a manner that is consistent and nurturing. Facilitators designed the program to deliver education, resources, and support to individuals with a goal of improving the skills of incarcerated parents to a more 
confident and supportive level for their children and families.

Listening to the articulated experiences of the offenders during class discussions allowed us a better understanding of their thoughts, worries, and personal struggles as incarcerated fathers. The PAT facilitators encouraged a safe environment where the offenders could share their thoughts and feelings about parenting without fear of judgement or repercussion, which created a medium for detailed, expressive open-ended dialogue that allowed us to document their perspective on parenting needs and develop a detailed picture of relevant patterns and themes. We organized these into three categories of data content: offender self-perception of parenting and reception to parenting education; skills offenders seek when wanting to be an effective parent; and the role of PAT in mending, encouraging, and enhancing relationships between children and their incarcerated fathers.

\subsection{Offender Self-Perception of Parenting and Reception to Parenting Education}

Participants frequently acknowledged how much they loved their children and sought to align themselves as allies to children, whom they perceived as being more authentic and less damaged by the society in general. "You can't change kids," one participant observed. "They will run to you if they see you're 'the Real Deal.' They know if you're Fake." Fathers also attributed higher intelligence to children than to most adults, though sometimes this looked like tactics of manipulation. "Oh yeah, they're smarter than we are. They know how to push the buttons to get what they want." Occasionally, the effort to align with children appeared to cause conflict in co-parenting relationships. Some fathers prided themselves on being the "easy" parent: "I'm a good, sweet daddy. They momma tell me I'm a pushover. She always yelling. But I'd rather they see me like the good one."

In some sessions, participants appeared to assume that the best way to be good allies to children was to be overly indulgent, spend money, or treat them to opportunities to attend events or recreational activities. A participant said, "I love children. We goin' [to a Six Flags amusement park]. If I got money, yeah, we goin'." On another occasion, a participant said, "I don't spank. Ever. I say, 'Hey, let's go get candy.' They like me because I take them to get candy." Showering children with affection was valued, but only to a certain point, "I always kiss my kids to death, but then they get tired of it when they get big enough. They tell you to quit."

Another theme that ran through participants' perception of parenting was that their own experiences being raised by distracted parents who did not spend much time (over)thinking about "how to parent" was a superior model to what they perceived as the current preoccupation with coddling children. "I got told once," commented one participant. "You might get hit by a car when you run away, saying why why why? Kids need to care about what I say, that's enough." In some cases, strict authoritarian discipline was equated to love for the well-being of the children. "We got whooped. Daddy would come in and whip us if we got out of line. I think that discipline showed he loved us. He didn't have to do that." Sometimes, these narratives about the relative ease of parenting in a different time took on a strongly nostalgic tone combined with a critique of state interference: "Kids have the three-letter afflictions, like ADD or ADHD or something. Hey, that's just being a kid! When I was a kid, we just got out there to burn up steam. Play cops and robbers. Run. Now all these kids are cooped up with these electronics. You're walking through Walmart, there's some kid screaming and no one does nothing. Everyone thinks DFS will come if you discipline your own kid."

Fathers also strongly differentiated the parenting strategies needed for girls from boys, and there was often discussion of different activities that were appropriate for daughters and mothers. "Dads need to nurture differently. We roughhouse. Moms can't do that," asserted one participant. Outlining these ideal daughter/father activities carved out a unique space that offender fathers believed they shared with their girl children. Another father shared, "My daughter, she love ballet for real. She always jumping, twirling, wearing a tutu, bedazzled. I wear all that pink. I put on that little crown. I love my daughter. I can't wait to go home." Older girls, too, had special relationships with their fathers. "My girls are teenagers now, and they don't like anyone to see me, but when we in the car, we turn up them "Girl Power" songs! We blastin' it! The more time I spend with them, the more they want to tell me about. They will tell me all the stuff. They will even show me photos on their phone."

One morning, a participant realized it was his son's twelfth birthday. The facilitator urged him to write a letter, and the participant shook his head. "No, man, he's in the sixth grade. It's too much drama. He's always telling me about his little girlfriend. I don't have no advice for that." While these fathers held fast to traditional notions of gender, they also expressed pride at daughters who challenged gender roles. "I got me one little girl; she thinks she's Spiderman. Ha ha! She climbs all over them boys and they can't do nothing."

\subsection{What Skills Do Offenders Seek When Wanting to Be an Effective Parent?}

Facilitators often framed the group sessions as a way for the fathers to learn "tools" that would help them to be more strategic parents, less reactive to challenging situations. "This is why we're here," a facilitator said when ending a group session, "To get tools. It's like a tool belt. When you go home after this, you need to be able to use all those tools. Stop. 
Think. Have a plan. Don't react without a plan. You may not change everything in your child's life, but you've modeled something for your child." Participants often indicated their receptiveness to messages through nodding at topic prompts, or by volunteering information about their own lives to further discussion. Facilitators left a good deal of space for participants to direct the conversations within the topics designated for that day. For example, one discussion dealt with boundary setting. Facilitators listened to shared anecdotes for several minutes, and then deftly moved to reframe the conversation from the abstract to a training session about "skills" that would help participants to recognize and implement boundaries in their lives. "I've heard a few of you say that you wanted your own parents to set more clear boundaries when you were younger. Boundaries help us to learn self-control. It's how we learn to self-regulate. It's hard as a parent to be consistent about this. Let's talk about how we can set boundaries for ourselves and for our children." Another session focused on nurturing. Participants were asked to share experiences from their own childhoods when their parents failed to nurture them. After several participants shared, the facilitators summarized a variety of potential nurturing strategies asked participants to think about ways they could nurture themselves and their children by remembering unexpected moments in their lives when they responded deeply to another person. A participant summarized the day's lesson by stating, "When you go through bad, you want to see good and do good for others."

Sometimes during the group sessions, facilitators pushed back on negative assertions by participants, even enlisting the participation of other group members to reframe and challenge learned systems of reactive behavior. For example, one participant discussed at length how he planned to teach his 11-year old daughter how to fight. He saw this as a valuable skill, necessary for children in his neighborhood. He said, "Yeah, man, I am teaching my daughter how to throw hands. The right way. She need to learn to fight in this world." When the facilitator pointed out that this could potentially be a mixed message about sanctioning violence, the participant defended his position. He explained, "Where I come from, you have to know how to fight." The facilitator gently probed this belief. She asked the participants to think about other things they could teach their daughters and asked if there were skills that might be shared that would allow these girls to deal with conflict in more effective ways. As happened in several cases, at the prompting of the facilitator, other participants offered suggestions of ways that the father could reimagine a parenting dilemma. Another participant coached, "Violence is not always that answer, man. Conversations and sometimes apologies are going to work better any day." Yet another participant supported the original father, arguing, "Where we grew up, you have to defend yourself." The facilitator nodded, and said, "But if you want change, it has to start with you. You are your child's first teacher." She also acknowledged the work that the participants were contributing, by simply attending the group to discuss parenting. She said, "You have so much power. You're their dad."

\subsection{The Role of PAT in Mending, Encouraging, and Enhancing Relationships Between Children and Their Incarcerated Fathers}

The past decade has seen a shift in the focus on deadbeat dads and their deficient role in the development of their children, to a more positive search for and emphasis on the need to transform the image of fatherhood into one of nurturing, emotional support, and ever important presence in the lives of their families. This shift has become manifest in television ads and programming depicting fatherhood in an important and positive light, policy changes that have incorporated laws to allow family leave for fathers of newborns, and research findings that support the importance of fathers as parental figures for their children's physical, emotional and social wellbeing (Yogman \& Garfield, 2016) . The current study provides support for this model of understanding and highlights the need for programming that enhances the relationship between incarcerated fathers and their children during their period of absence and while transitioning back into society and their family roles.

Each one-hour class was filled with questions, confessions, communications, and emotions around diverse topics relating to becoming a more effective parent and role model for the inmates' children. Sessions began with inmates signing in and printing the names and ages of their children. The ages of fathers varied dramatically, from very young to grandfather aged. Offenders had between one and eleven children. The facilitator of the class introduced the subject and then asked each inmate participant to share their insight and understanding of the subject, opening dialogue in a way that was intuitive, open ended, constructive, and free of personal judgement while still allowing for the transmission of information, guidance, and correction. During our observations, several themes emerged connecting the role of this program in providing offenders with the opportunity to more effectively exercise parenting during their period of incarceration and become more effective parents once released.

One emerging theme that was the focus of conversation was that of "Intentional Conversations." During this lesson, discussion surrounded the importance of modeling appropriate behavior for children, being honest, and avoiding mixed messages. There were several moments where the inmates expressed the lack of clear guidance and understanding of "what to say" to their kids and "how to get them to talk" during their iPad facilitated visitation times at the GCJ. At the core of this discussion, sentiments of discouragement, remorse and shame emerged amongst the fathers, expressing a lack of understanding or ability to, as one inmate put it "take my own advice." Another inmate expressed a sense of failure in 
communicating with their children, indicating "I don't want them to be like me." Others admitted they believed their children were better off without them. These anxieties can stifle the potential for bonding with children during periods of separation and further dilute the presence of fathers in the lives of their children and their role as effective parents (Folk et al., 2019).

During these discussions, facilitators elaborated on misperceptions and corrections to develop meaningful, intentional conversations with children that go beyond the daily, repetitive questions of what they ate, how they felt, and how their cases were going. Things are not always okay; rather, involve children in relevant issues and problems, ask for their opinion, take their advice when appropriate, empower them with the truth, and promise them a judgement free response. As Shari explained, "Sometimes it's ok to just tell them 'I'm just happy to talk to you' or 'I'm so excited to hear your voice' to reinforce that they are on your mind, in your thoughts, and continue to be a part of your life despite the problems and hardships you are facing." This seemed to be a source of encouragement and relief to the inmates and provided them with a clearer picture of what kids need to hear, how much information they should know, and how to decipher between being honest and protecting them.

Another emerging theme of particular significance was that of "Parenting Makes A Difference." Most offenders participating in the classes during our period of observations indicated that they came from families with poor parental role models. The stories were different, but indicators of neglect, abuse, addiction, and criminal involvement were predominant in most of them, with these experiences leading to feelings of distrust, disillusionment, and the hopeless despair of any better future interaction with their own children. One inmate elaborated, "I don't know how to break the cycle...at 14 years old, my dad was the first person to shoot me with dope; my parents locked themselves in the shed doing drugs...I wouldn't see them for several days." Another inmate also explained, "My mom had to be a dad and a mom because my dad was in prison for the first 21 years of my life; I don't trust anyone...One time, I got beaten by this dude my mom was seeing... upside down naked with a stick, for something I didn't even do."

Experiences from childhood were a clear roadblock to the ability of inmate fathers to believe they were positive, nurturing parents for their own children. As one offender put it, “I don't know how to be a parent because I don't know how to discipline my kids anymore." The facilitators listened intently to their stories, and then explained the importance of distancing their own roles as parents, and their potential for successfully impacting the lives of their children, with their experiences growing up and the traumas they faced as children. Shari's response to these encounters, "history does not have to repeat itself," seemed to provide the distraught offenders a glimmer of hope, along with guidance on how to become a nurturing parent by identifying their own strengths. The class proceeded to go around the table in answer to the question, "What are you good at in terms of being a parent"? Inmates noted, "I let my kids show emotions," "I answer their questions," "I like to talk to them and teach them, because they're little and don't know much." Highlighting the importance of their role as nurturing parents, even from jail, emphasized the relevance of this dynamic in repairing broken relationships with children and ensuring the development of positive exchanges during visitation that can reinforce their parenting role and enhance its continuity upon release (Charles et al., 2019).

A third impactful theme that emerged during our observation of the PAT classes at the GCJ was "Healthy Relationships." Through various dialogues and conversations, it was quite apparent that many of the participating offenders did not have a clear perception of the concept of a "healthy relationship." For example, when asked, one offender indicated that they passed down their skills to their daughter by "teaching her how to fight," genuinely feeling that he was doing something positive and meaningful. Other inmates indicated a lack of confidence in their ability to have any form of healthy relationships, feeling stripped of any form of dignity, self-respect, and manhood because of their personal struggles with incarceration. As put by one inmate, "it's hard to have a relationship of any sort when you have to parent through video chat...." Empowering these offenders was the key to rebuilding their confidence and sustaining their ability to become effective parents, and with that, Shari redirected their attention and thought process to what they still "have" that "can't be taken away"?

This opened the discussion to a rich and meaningful dialogue surrounding the role of knowledge and its use to transmit emotions and feelings to children, as well as provide constructive criticism, encouragement, and parental advice. They began to see the hallmark of healthy relationships as developing the ability to communicate with their children, in any format or medium, in a safe, open, and accepting way. One inmate noted, "knowledge is the only thing [they] can't take away from me," and another, illustrated the importance of knowledge by stating "knowledge is not for free...people that don't listen...they're time thieves." Armed with that insight, the lesson continued to build upon the role of recognizing their own talents and abilities, developing parenting skills, and becoming effective leaders as tools in their "toolbelt of knowledge" to build healthy relationships with their children and families. At the end of class, one participant leaving the room looked back and exclaimed, "I guess relationships are more than just providing entertainment." 


\section{Discussion and Suggestions for Future Research}

This study provides an initial perspective on the value of offering parenting classes to incarcerated fathers as a potential mechanism for improving and maintaining effective bonds with their children upon reentry to the community. We explored the logistics and efficacy of a program designed to mend, encourage, and enhance relationships between children and their incarcerated fathers, by providing support for an educational model that understands and highlights the need for attention to relationships between incarcerated fathers and their children during the period of absence and prompting skills that can be useful to fathers when transitioning back into society and their family roles. Rather than a focus on "deadbeat dads," this programming shows promise that incarcerated men actively search for and emphasize a desire to transform their own expectations of fatherhood into skills designed to nurture and provide emotional support in their families.

During our study, we discovered three promising themes in the processing of programming focusing on addressing deficits in the parental role of incarcerated fathers and their desire to establish a healthy, nurturing relationship with their children during the period of their absence. First, fathers sought to improve their capacity to engage in "intentional conversations," where they learned about modeling desirable behavior, being honest, and avoiding giving children mixed messages. Second, fathers began the uncomfortable process of unpacking their own childhoods and overcoming poor parental models as they realized that "parenting makes a difference." Considering additional challenges, such as violence, neglect, substance abuse, and criminal involvement, these fathers were encouraged to develop a "toolkit" of more positive parenting responsibilities and responses. Finally, fathers were introduced to the idea of "healthy relationships," including creating strong boundaries and new types of relationship knowledge. This, despite the fact that it may be difficult, challenge their own image of self, and make them feel vulnerable and uncomfortable.

Clearly, this is just the beginning of what could potentially become a much larger investigation. While there may be limitations to the generalizability of our study, our ability to share the articulated experiences of the offenders during class discussions gives tremendous insight into their thoughts and personal struggles as incarcerated fathers. We also recognize the need for facilitators in this type of programming to create a safe environment where participating offenders can share their thoughts and feelings about parenting without fear of judgement or repercussion. We share this expressive, open-ended dialogue here to invite more attention and interest in this type of innovative programming, recognizing its imperative role in the successful reentry of prisoners to society and the impact it has on the future of children of incarcerated offenders.

Declaration of Interests Statement - This manuscript was not supported by any agency or grant funding and does not entail any financial interest or benefit to the authors, facilitators, or offenders.

\section{References}

Arditti, J. A. (2012). Parental incarceration and the family: Psychological and social effects of imprisonment on children, parents, and caregivers. NYU Press.

Arditti, J., Smock, S. A., \&Parkman, T. S. (2005). "It's hard to be a father": A qualitative exploration of incarcerated fatherhood. Fathering, 3(3), 267-288. https://doi.org/10.3149/fth.0303.267

Boswell, G. (2018). Imprisoned fathers and their children: A reflection on two decades of research. Child Care in Practice, 24(2), 212-224. https://doi.org/10.1080/13575279.2017.1420037

Britto, P. R., Lye, S. J., Proulx, K., Yousafzai, A. K., Matthews, S. G., Vaivada, T., \& MacMillan, H. (2017). Nurturing care: promoting early childhood development. The Lancet, 389(10064), 91-102. https://doi.org/10.1016/S0140-6736(16)31390-3

Cabrera, N. J., Volling, B. L., \& Barr, R. (2018). Fathers are parents, too! Widening the lens on parenting for children's development. Child Development Perspectives, 12(3), 152-157. https://doi.org/10.1111/cdep.12275

Charles, P., Muentner, L., \& Kjellstrand, J. (2019). Parenting and incarceration: Perspectives on father-child involvement during reentry from prison. Social Service Review, 93(2), 218-261. https://doi.org/10.1086/703446

Child Welfare Information Gateway. (2019). Parent education to strengthen families and prevent child maltreatment. US Department of Health and Human Services, Children's Bureau. Retrieved from https://www.childwelfare.gov/pubs/issue-briefs/parented/

Comfort, M. (2009). Doing time together: Love and family in the shadow of prison. University of Chicago Press. https://doi.org/10.7208/chicago/9780226114682.001.0001

Craigie, T. A., Pratt, E., \& McDaniel, M. (2018). Father reentry and child outcomes. The Urban Institute.

Dyer, W. J., Pleck, J. H., \& McBride, B. A. (2012). Imprisoned fathers and their family relationships: A 40-year review from a multi-theory view. Journal of Family Theory and Review, 4, 20-47. 
https://doi.org/10.1111/j.1756-2589.2011.00111.x

Edin, K., Nelson, T. J., Butler, R., \& Francis, R. (2019). Taking care of mine: Can child support become a family-building institution? Journal of Family Theory \& Review, 11(1), 79-91. https://doi.org/10.1111/jftr.12324

Folk, J. B., Stuewig, J., Mashek, D., Tangney, J. P., \& Grossmann, J. (2019). Behind bars but connected to family: Evidence for the benefits of family contact during incarceration. Journal of Family Psychology, 33(4), 453. https://doi.org/10.1037/fam0000520

Fontaine, J., Cramer, L., Kurs, E., Paddock, E., Eisenstat, J., Levy, J., \& Reginal, T. (2017). Final implementation findings from the responsible fatherhood reentry projects. (Report No. 2017-05.) US Department of Health and Human Services. Retrieved from

https://www.acf.hhs.gov/opre/resource/final-implementation-findings-from-the-responsible-fatherhood-reentry-pro jects

Fox, B., Verona, E., \& Fournier, L. (2019). Psychological assessment of risk in a county jail: implications for reentry, recidivism, and detention practices in the USA. Journal of Criminal Psychology, 9(4), 173-186. https://doi.org/10.1108/JCP-11-2019-051

Hairston, C. F. (2017). The forgotten parent: Understanding the forces that influence incarcerated fathers' relationships with their children. In Children with parents in prison (pp. 149-171). Routledge. https://doi.org/10.4324/9781315081359-9

Hansen, G. V. (2017). "Fathers in Prison" program may create a basis for desistance among Norwegian prisoners. Journal of Offender Rehabilitation, 56(3), 173-187. https://doi.org/10.1080/10509674.2017.1290008

Haskins, A. R. (2015). Paternal incarceration and child-reported behavioral functioning at age 9. Social Science Research, 52, 18-33. https://doi.org/10.1016/j.ssresearch.2015.01.001

Haskins, A. R. (2017). Paternal incarceration and children's schooling contexts: Intersecting inequalities of educational opportunity. The ANNALS of the American Academy of Political and Social Science, 674(1), 134-162. https://doi.org/10.1177/0002716217732011

Hayashi Jr, P., Abib, G., \& Hoppen, N. (2019). Validity in qualitative research: A processual approach. The Qualitative Report, 24(1), 98-112. https://doi.org/10.46743/2160-3715/2019.3443

Henkhaus, L. E. (2019). The Child Left Behind: Parental Incarceration and Adult Human Capital in the United States. In AEA Papers and Proceedings (Vol. 109, pp. 199-203). https://doi.org/10.1257/pandp.20191092

Houck, K. D., \& Loper, A. B. (2002). The relationship of parenting stress to adjustment among mothers in prison. American Journal of Orthopsychiatry, 72(4), 548-558. https://doi.org/10.1037/0002-9432.72.4.548

Huser, M., Small, S. A., \& Eastman, G. (2008). What research tells us about effective parenting education programs. (Report). University of Wisconsin-Madison Division of Extension. Retrieved from https://fyi.extension.wisc.edu/whatworkswisconsin/files/2014/04/factsheet_4parentinged.pdf

Jardine, C. (2017). Constructing and maintaining family in the context of imprisonment. British Journal of Criminology, 1-19. https://doi.org/10.1093/bjc/azx005

Jeffries, J. M., \& Menghraj, S. (2016). Serving incarcerated and ex-offender fathers and their families: A review of the field. (Report). Vera Institute of Justice. Retrieved from

https://www.vera.org/publications/serving-incarcerated-and-ex-offender-fathers-and-their-families-a-review-of-thefield

Johnson, T., Selber, K., \& Lauderdale, M. (2017). Developing quality services for offenders and families: An innovative partnership. In Children with Parents in Prison (pp. 127-148). Routledge. https://doi.org/10.4324/9781315081359-8

Lee, R. D., Fang, X., \& Luo, F. (2013). The impact of parental incarceration on the physical and mental health of young adults. Pediatrics, 131(4), Article e1188-e1195. https://doi.org/10.1542/peds.2012-0627

McKay, T., Corwin, E., Herman-Stahl, M., Bir, A., Lindquist, C., Smiley-McDonald, H., \& Siegel, S. (2010). Parenting from prison: Innovative programs to support incarcerated and reentering fathers. US Department of Health and Human Services, Administration for Children and Families.

McKay, T., Feinberg, R., Landwehr, J., Payne, J., Comfort, M., Lindquist, C. H., ... \& Bir, A. (2018). "Always having hope": Father-child relationships after reentry from prison. Journal of Offender Rehabilitation, 57(2), 162-187. https://doi.org/10.1080/10509674.2018.1441206

McKay, T., Lindquist, C., Corwin, E., \& Bir, A. (2015). The implementation offamily strengthening programs for families 
affected by incarceration. US Department of Health and Human Services.

McLeod, B. A., Johnson Jr, W. E., Cryer-Coupet, Q. R., \& Mincy, R. B. (2019). Examining the longitudinal effects of paternal incarceration and coparenting relationships on sons' educational outcomes: A mediation analysis. Children and Youth Services Review, 100, 362-375. https://doi.org/10.1016/j.childyouth.2019.03.010

Middlemass, K. M., \& Smiley, C. (2019). Prisoner Reentry in the 21st Century: Critical Perspectives of Returning Home. Routledge. https://doi.org/10.4324/9781351138246

Miller, R. R. (2018). Impacts of incarceration on the African American family. Routledge. https://doi.org/10.4324/9780203789001

Mitchell, M. B., Dodson, K. D., \& Cabage, L. N. (2018). Parenting behind bars: The experiences of incarcerated mothers and fathers. In Routledge Handbook on Offenders with Special Needs (pp. 124-140). Routledge. https://doi.org/10.4324/9781315626574-8

Mohajan, H. K. (2018). Qualitative research methodology in social sciences and related subjects. Journal of Economic Development, Environment and People, 7(1), 23-48. https://doi.org/10.26458/jedep.v7i1.571

Murphy, D., \& P. Mae Cooper. (2015). Parents Behind Bars: What Happens to Their Children? Bethesda, MD: Child Trends.

NASEM. National Academies of Science, Engineering, and Medicine. (2016.) Parenting Maters: Supporting Parents of Children Ages 0-8.

Nutbrown, C., Clough, P., Stammers, L., Emblin, N., \& Alston-Smith, S. (2019). Family literacy in prisons: fathers' engagement with young children. Research papers in education, 34(2), 169-191.

https://doi.org/10.1080/02671522.2017.1402085

Palm, G. (2018). Parent education for incarcerated fathers. In Clinical and educational interventions with fathers (pp. 117-141). Routledge. https://doi.org/10.4324/9781315786247-6

Rothe, M. I., Rogers-Tanner, S., \& Skrypek, M. (2016.) “The Benefits of Parenting Education: A Review of the Literature for the Wilder Parent Education Center.” Report. Retrieved from https://www.wilder.org/sites/default/files/imports/LitReviewSummary_10-16.pdf

Sanders, M. R., Kirby, J. N., Tellegen, C. L., \& Day, J. J. (2014). The Triple P-Positive Parenting Program: A systematic review and meta-analysis of a multi-level system of parenting support. Clinical psychology review, 34(4), 337-357. https://doi.org/10.1016/j.cpr.2014.04.003

Sippel, L. M., Pietrzak, R. H., Charney, D. S., Mayes, L. C., \& Southwick, S. M. (2015). How does social support enhance resilience in the trauma-exposed individual? Ecology and Society, 20(4). https://doi.org/10.5751/ES-07832-200410

Spiers, J., Morse, J. M., Olson, K., Mayan, M., \& Barrett, M. (2018). Reflection/Commentary on a Past Article:"Verification Strategies for Establishing Reliability and Validity in Qualitative Research. International Journal of Qualitative Methods, 17(1), 1609406918788237. https://doi.org/10.1177/1609406918788237

Tracy, S. J. (2019). Qualitative research methods: Collecting evidence, crafting analysis, communicating impact. John Wiley \& Sons.

Turney, K., \& Goodsell, R. (2018). Parental incarceration and children's wellbeing. The Future of Children, 28(1), 147-164. https://doi.org/10.1353/foc.2018.0007

U.S. Department of Health and Human Services. (2017). Multi-site family study on Incarceration, Parenting and Partnering. (Report). Retrieved from

https://aspe.hhs.gov/pdf-report/multi-site-family-study-incarceration-parenting-and-partnering-program-impacts-te chnical-report .

Visher, C. A., \& Courtney, S. M. (2007). One year out: Experiences of prisoners returning to Cleveland. (Report). Urban Institute Justice Policy Center. https://doi.org/10.1037/e719862011-001

Visher, C. A., Bakken, N. W., \& Gunter, W. D. (2013). Fatherhood, community reintegration, and successful outcomes. Journal of Offender Rehabilitation, 52(7), 451-469. https://doi.org/10.1080/10509674.2013.829899

Visher, C. A., Yahner, J., \& Jennifer La Vigna, N. (2010). Life after prison: tracking the experiences of male prisoners returning to Chicago, Cleveland, and Houston. Washington, DC: The Urban Institute. https://doi.org/10.1037/e718972011-001

Wilson, C. M. (2013). If you listen, I'll tell you how I feel: incarcerated men expressing emotion through songwriting. [Unpublished doctoral dissertation]. University of Iowa. 
Yogman, M., \& Garfield, C. F. (2016). Fathers' roles in the care and development of their children. Pediatrics, 138(1), Article e20161128. https://doi.org/10.1542/peds.2016-1128

Yong, V. (2016). An exploratory study on the reintegration route of ex-drug convicts: obstacles leading to re-entry and proposed policies to prevention of re-entry. [Thesis, Nanyang Technological University]. Retrieved from https://www.slideshare.net/VanessaYong4/an-exploratory-study-on-the-reintegration-route-of-exdrug-convicts

\section{Copyrights}

Copyright for this article is retained by the author(s), with first publication rights granted to the journal.

This is an open-access article distributed under the terms and conditions of the Creative Commons Attribution license which permits unrestricted use, distribution, and reproduction in any medium, provided the original work is properly cited. 